\title{
Optimal management of posterior cruciate ligament injuries: current perspectives
}

\author{
This article was published in the following Dove Press journal: \\ Orthopedic Research and Reviews \\ 5 April 2017 \\ Number of times this article has been viewed
}

\author{
K Donald Shelbourne' \\ Rodney W Benner' \\ Jonathan D Ringenberg ${ }^{2}$ \\ Tinker Gray' \\ 'Orthopaedic Surgeon, Shelbourne \\ Knee Center, ${ }^{2}$ Indiana University \\ School of Medicine, Indianapolis, \\ IN, USA
}

\begin{abstract}
Background: The optimal management of posterior cruciate ligament (PCL) injuries is debated by orthopedic surgeons. A natural history study (NHS) of acute, isolated PCL tears in patients with a mean follow-up of 14.3 years was previously published. The purpose of this study was to compare and contrast the results of the NHS study with those of other studies with similar follow-up time after operative and nonoperative management of isolated PCL tears.
\end{abstract}

Material and methods: With reviewing the literature, six operative management and six nonoperative management studies were found for treating isolated PCL injuries. We analyzed the subjective and objective outcomes of these 12 studies and compared them to the results of the NHS to determine optimal management of PCL injuries.

Results: Final follow-up times ranged from a mean of 6.2 to 15 years in the nonoperative studies and 6.3 to 12 years in the operative studies. Side-to-side differences in laxity following surgical management ranged from 1.1 to $7 \mathrm{~mm}$ on KT-1000 arthrometer testing and 2.8 to $4.7 \mathrm{~mm}$ on Telos stress testing. Tegner scores at final follow-up ranged from 6.6 to 7.7 in nonoperative studies and 5.7 to 7.4 in operative studies. International Knee Documentation Committee scores were 73.4, 82.7, and 84 in nonoperative studies and 65 and 87 in the operative studies. Lysholm scores were 85.2 in the nonoperative study and ranged from 81 to 92.1 in operative studies. Osteoarthritis was reported with ranges from $17 \%$ to $88 \%$ in nonoperative studies and $13.3 \%$ to $63.6 \%$ in operative studies.

Conclusion: We found that the subjective and objective results in the NHS compare favorably to those of outcomes for PCL reconstruction. Unless a technique is found that can completely restore knee stability, it is unlikely that simply reducing posterior laxity will improve outcomes or prevent the development of osteoarthritis.

Keywords: posterior cruciate ligament injuries, management, long-term outcomes

\section{Introduction}

The optimal management of posterior cruciate ligament (PCL) injuries remains a topic of debate among orthopedic surgeons. Many authors recommend conservative management for isolated PCL injuries due to good subjective and functional outcomes. ${ }^{1-6}$ Surgical management for PCL injuries is often recommended when there are associated ligament injuries or when patients have persistent pain and instability despite nonoperative management. ${ }^{7-13}$ Recently, PCL reconstruction has become a more common choice of treatment. Given that some studies showed worsening symptoms and an increase in degenerative changes with time, ${ }^{14-16}$ more surgeons are recommending PCL reconstruction for high-grade isolated tears. ${ }^{17-21} \mathrm{PCL}$ reconstruction is aimed at restoring knee stability and preventing early onset of osteoarthritis. ${ }^{22}$ It
Correspondence: K Donald Shelbourne Shelbourne Knee Center, I500 N. Ritter Ave, Suite 500, Indianapolis, IN, USA Tel +l 3179248636

$\mathrm{Fax}+13179210230$

Email Egray@ecommunity.com 
is assumed that reduction of the posterior laxity following PCL tears will improve short-term and long-term outcomes; however, restoring normal knee stability with reconstruction following PCL tears has yet to be achieved reliably. ${ }^{17,19,23-33}$ PCL reconstruction has shown good results in being able to reduce posterior laxity; however, it is still unknown whether simply reducing PCL laxity without complete stabilization will improve the subjective results or prevent osteoarthritis compared to nonoperative management. ${ }^{3,4,6}$ Given that surgery adds significant risk to patients, it should improve upon the results of nonoperative management.

Only a few studies, however, have prospectively studied the natural history of PCL tears. ${ }^{3,4,5,33}$ Most studies of nonoperative treatment have been retrospective and were of patients who sought treatment of chronic PCL laxity and painful symptoms or include patients with multiple knee ligament injuries. ${ }^{1,15,16,35}$ These studies do not give a true picture of the natural history of isolated PCL injuries and may represent a worse outcome than would be found from evaluating a population of patients prospectively after an acute, isolated PCL tear.

To compare the results of nonoperative and operative management, we must first understand the true natural history of a PCL injury. Shelbourne et al, published a prospective, longterm natural history study (NHS) of patients after an acute, isolated PCL injury with minimum 10-year follow-up (average 14.3 years). ${ }^{4}$ Only a few studies on management of isolated PCL injuries have reported similar long-term follow-ups, with most studies showing results at only $2-5$ years. ${ }^{17-19,24,27,32,36-43}$ The purpose of this review is to compare and contrast the subjective and objective results of the NHS by Shelbourne et $\mathrm{al}^{4}$ (NHS) with those of other operative and nonoperative studies with similar long-term follow-up.

\section{Method for review}

The NHS $^{4}$ was a continuation of a previous study ${ }^{3}$ that evaluated 68 patients ( 13 female, 55 male) who were prospectively followed for acute, isolated PCL tears. They underwent nonoperative treatment and performed several subjective and objective evaluations throughout their follow-up period. The mean age at the time of injury was 26.2 years (range: 9.6-60.0 years). Forty-four patients were available for both objective and subjective evaluations at a minimum 10-year follow-up and mean of 14.3 years (range: 10-21 years) after injury; 68 patients completed subjective evaluations with a mean of 17.6 years from injury.

To compare and contrast the $\mathrm{NHS}^{4}$ results with those of other studies, a literature search of PubMed and OVID was performed to search for PCL treatment studies with long-term outcomes, as a way to compare the NHS to other studies of treating isolated PCL tears with similar follow-up times. Only a few studies had follow-up times $>10$ years after treatment. Therefore, the criteria were expanded to include studies with at least 6 years of follow-up; 12 articles were found that evaluated treatment of isolated PCL tears with reports of subjective and/or objective outcomes at followup times $>6$ years. The methods of these studies were read carefully to assure that the criteria excluded for any other ligamentous laxity. Six of these articles reported results following nonoperative management, ${ }^{1,5,6,14,15}$ and six articles reported results following operative management. ${ }^{25,26,28-30,44}$ Table 1 shows each long-term study compared in this study and their treatment and follow-up times.

\section{Results Healing potential}

When determining the optimal management of PCL injuries, it is important to first recognize that, unlike the anterior cruciate ligament (ACL), the PCL has been shown to have a natural, healing ability. ${ }^{45-50}$ Better synovial coverage and blood circulation, compared to that of the ACL, allows the PCL to regain or maintain magnetic resonance imaging (MRI) continuity in most patients with PCL injuries. Continuity of the PCL was found in 20 of 21 patients at 6 months after treatment with a dynamic anterior drawer brace. ${ }^{47}$ Tewes et $\mathrm{al}^{50}$ reported on a series of 13 patients treated nonoperatively, 10 of whom showed PCL continuity on MRI. Even with high-grade tears or tears associated with other ligament damage, Shelbourne et $\mathrm{al}^{49}$ found that most will heal with nonoperative treatment. In their evaluation of 40 patients at an average follow-up of 3.2 years, all 18 low-grade and midgrade injuries and 19 of the 22 high-grade injuries healed with continuity. All 6 of the low-grade and mid-grade injuries associated with other ligament damage revealed continuity and of the 11 high-grade injuries with associated ligament damage, only one PCL failed to regain continuity.

Although these studies report healing of the PCL, none could show a correlation between MRI continuity and clinical stability. Ahn et $\mathrm{al}^{45}$ showed that 27 of 38 knees had regained continuity on MRI, and that patients with PCL continuity showed statistically less posterior instability on follow-up physical examination and KT-1000 arthrometer testing. A prospective study of 17 patients treated with 6 weeks of cylinder cast immobilization followed by 6 weeks with a PCL brace showed a decrease in mean side-to-side difference on 
Table I Summary of studies reviewed

\begin{tabular}{|c|c|c|}
\hline & $\begin{array}{l}\text { Follow-up } \\
\text { (years) }\end{array}$ & Management \\
\hline \multicolumn{3}{|l|}{ Natural history study } \\
\hline Shelbourne et al ${ }^{4}$ & 14.3 & $\begin{array}{l}68 \text { patients with isolated } \mathrm{PCL} \text { tears treated nonoperatively with a home rehabilitation } \\
\text { program focusing on ROM and strength }\end{array}$ \\
\hline \multicolumn{3}{|c|}{ Comparative nonoperative studies } \\
\hline Dejour et al ${ }^{15}$ & 15 & 45 patients with isolated $\mathrm{PCL}$ tears treated with varied immobilization and physiotherapy \\
\hline Boynton and Teitjens ${ }^{14}$ & 13.4 & 38 patients with isolated $\mathrm{PCL}$ tears treated nonoperatively \\
\hline Shelbourne and Muthukaruppan ${ }^{5}$ & 7.8 & $\begin{array}{l}215 \text { patients with isolated } \mathrm{PCL} \text { tears were treated with a home rehabilitation program } \\
\text { focusing on reduction of swelling and restoring normal gait and knee motion }\end{array}$ \\
\hline Dandy and Pusey' & 7.2 & $\begin{array}{l}20 \text { patients with isolated PCL tears treated with early mobilization or plaster } \\
\text { immobilization }\end{array}$ \\
\hline Patel et $\mathrm{al}^{34}$ & 6.9 & $\begin{array}{l}57 \text { patients ( } 58 \text { knees) with isolated } \mathrm{PCL} \text { tears treated with quadriceps muscle } \\
\text { rehabilitation with or without bracing and a home-based rehabilitation program }\end{array}$ \\
\hline Parolie and Bergfeld ${ }^{6}$ & 6.2 & $\begin{array}{l}25 \text { athletes with isolated PCL tears, acute tears were treated with rehabilitation and a } \\
\text { Lenox Hill Brace, chronic tears were treated in a variety of ways }\end{array}$ \\
\hline \multicolumn{3}{|l|}{ Comparative operative studies } \\
\hline Song et $\mathrm{al}^{44}$ & 12 & $\begin{array}{l}66 \text { patients with isolated PCL tears, } 36 \text { patients underwent reconstruction using a } \\
\text { transtibial technique with hamstring tendon graft and } 30 \text { patients underwent a tibial inlay } \\
\text { technique with a patellar tendon graft }\end{array}$ \\
\hline Jackson et $\mathrm{a}^{26}$ & 10 & $\begin{array}{l}26 \text { patients with isolated } \mathrm{PCL} \text { tears underwent surgical treatment with an endoscopically } \\
\text { assisted reconstruction using hamstring tendon autografts }\end{array}$ \\
\hline Hermans et $\mathrm{a}^{25}$ & 9.1 & $\begin{array}{l}25 \text { patients with isolated PCL tears were treated with anterolateral bundle } \\
\text { reconstruction with } 9 / 25 \text { treated with bone-patellar tendon-bone autograft, } 15 / 25 \text { with a } \\
\text { semitendinosus gracilis autograft, and } 1 / 25 \text { with an Achilles tendon allograft }\end{array}$ \\
\hline Shonet $\mathrm{al}^{30}$ & 7.5 & $\begin{array}{l}\text { I4 patients with isolated PCL tears who underwent a single bundle tibial inlay PCL } \\
\text { reconstruction }\end{array}$ \\
\hline Lipscomb et $a^{28}$ & 7.1 & $\begin{array}{l}25 \text { patients with isolated PCL tears underwent reconstruction of the PCL using the } \\
\text { semitendinosus and gracilis tendons alone or with an extraarticular procedure }\end{array}$ \\
\hline MacGillivray et a ${ }^{29}$ & 6.3 & $\begin{array}{l}\text { I3 patients with isolated PCL tears were treated surgically using a transtibial technique } \\
\text { with a single femoral tunnel }\end{array}$ \\
\hline
\end{tabular}

Abbreviations: $\mathrm{PCL}$, posterior cruciate ligament; ROM, range of motion.

posterior stress view from 7.4 to $3.5 \mathrm{~mm}$ and a decrease in mean side-to-side difference on KT-1000 arthrometer from 6.2 to $3.0 \mathrm{~mm} .{ }^{48}$ Studies that evaluated PCL healing have also shown the development of a firm endpoint in many PCL tears treated nonoperatively. ${ }^{3,4,46}$

\section{Laxity}

Despite the ligament's natural ability to heal, many studies on nonoperative treatment have found there to be some degree of residual knee laxity., ${ }^{3,4,53}$ The NHS found little change in laxity with time. Increased laxity from the initial examination was found in only $9 \%$ of patients and decreased laxity was found in only $16 \%$ of patients. ${ }^{4}$ Despite some residual laxity, most studies have shown that patients with PCL tears achieve good subjective results that are independent of the grade of laxity. ${ }^{3,4,5,34,45}$ The NHS showed good outcomes at a mean of 14 years after injury that were not statistically significantly different between grades of PCL laxity. ${ }^{4}$ Patel et $\mathrm{al}^{34}$ found no correlation between subjective scores and grades of PCL laxity at a mean follow-up of 6.9 years after injury. Shelbourne and Muthukaruppan ${ }^{5}$ evaluated 215 patients treated nonoperatively at a mean of 7.8 years and found no correlation between subjective scores and grade of laxity. Due to this lack of correlation between laxity and subjective results, it is likely that in order to improve upon the results of nonoperative management, surgical reconstruction would need to completely restore the knee to normal laxity. Although most studies have reported good outcomes in reducing posterior knee laxity, normal stability is rarely ever achieved. Among the studies under investigation in this paper, the three most common evaluations used to determine outcomes of laxity were the posterior drawer test, KT-1000 arthrometer, and Telos stress radiographs.

Postoperative clinical evaluations were described in five of the six long-term studies on operative management of PCL tears. ${ }^{25,26,30,44}$ Song et al, ${ }^{44}$ at a mean of 12 years, found that $83.3 \%-87 \%$ of patients in 2 groups had grade I laxity and the rest had grade II. Jackson et al, ${ }^{26}$ at 10 -year follow-up, showed that $36.4 \%$ of patients had grade 0 laxity, $54.5 \%$ had grade I laxity, and $9.1 \%$ had grade II laxity. Hermans et al, ${ }^{25}$ at 
9-year follow-up, found that posterior drawer testing revealed grade 0 in $9.1 \%$ of patients, grade I in $68.2 \%$, and grade II in $22.7 \%$. Shon et al, ${ }^{30}$ at 7.5 years, showed that 13 were grade I and 1 was grade II on physical examination. MacGillivray et al, ${ }^{29}$ at a mean follow-up of 6.3 years, found that only $38 \%$ of patients improved with respect to their grade following reconstruction with a transtibial technique.

The NHS revealed a mean KT-1000 arthrometer difference between the involved knee and noninvolved knee to range between 3.1 and $7.2 \mathrm{~mm} .{ }^{4}$ Studies on surgical management of PCL injuries have varied tremendously in the ability to reduce posterior laxity on KT-1000 arthrometer examinations. Among the long-term studies that reported KT-1000 arthrometer measurements, Jackson et $\mathrm{al}^{26}$ reported the lowest amount of residual laxity with a side-to-side difference of $1.1 \mathrm{~mm}$ and 17 of 20 patients having $<3 \mathrm{~mm}$ of difference. Table 2 shows the mean side-to-side difference on KT-1000 arthrometer reported by the other long-term studies.

Three of the long-term studies on operative management reported side-to-side measurements with Telos stress radiographs. Table 3 shows the preoperative results and results at final follow-up.

\section{Range of motion}

One concern with reconstruction of PCL injuries is the loss of range of motion. Few studies have evaluated knee range of motion following surgery, and the rate for range of motion deficits has been from $7 \%$ to $30 \%{ }^{17,26,30,32,33,51,52}$ All

Table 2 Summary of mean KT-1000 arthrometer values at follow-up

\begin{tabular}{ll}
\hline & $\begin{array}{l}\text { Mean KT- } 1000 \text { arthrometer side-to- } \\
\text { side difference at follow-up }(\mathbf{m m})\end{array}$ \\
\hline $\begin{array}{l}\text { Nonoperative studies } \\
\text { Patel et al }{ }^{34}\end{array}$ & 5.6 \\
$\begin{array}{l}\text { Parolie and Bergfeld } \\
\text { Operative studies }\end{array}$ & 7.1 \\
Jackson et al $^{26}$ & 1.1 \\
Hermans et al $^{25}$ & 2.1 \\
MacGillivray et al $^{29}$ & 5.9 \\
Lipscomb et al $^{28}$ & 6.3 acute group/7 chronic group \\
\hline
\end{tabular}

Table 3 Telos stress testing

\begin{tabular}{lll}
\hline Telos stress & $\begin{array}{l}\text { Preoperative } \\
\text { (mean) }\end{array}$ & $\begin{array}{l}\text { Postoperative } \\
\text { (mean) }\end{array}$ \\
\hline Shon et $\mathrm{a}^{30}$ & $9.5 \mathrm{~mm}\left(30^{\circ}\right.$ flexion $)$, & $2.8 \mathrm{~mm}\left(30^{\circ}\right.$ flexion $)$, \\
& $9.8 \mathrm{~mm}\left(90^{\circ}\right.$ flexion $)$ & $3.0 \mathrm{~mm}\left(90^{\circ}\right.$ flexion $)$ \\
Song et $\mathrm{a}^{44}$ & $10.1 \mathrm{~mm}$ transtibial, & $4.1 \mathrm{~mm}$ transtibial, \\
& $10.4 \mathrm{~mm}$ tibial inlay & $4.2 \mathrm{~mm}$ tibial inlay \\
Hermans et a ${ }^{25}$ & & $4.7 \mathrm{~mm}$ \\
\hline
\end{tabular}

of the patients in the NHS maintained normal knee range of motion. The mean range of motion for the PCL-injured knee was from $4^{\circ}$ of hyperextension to $138^{\circ}$ of flexion. The mean range of motion for the noninvolved knee was from $4^{\circ}$ of hyperextension to $137^{\circ}$ of flexion. ${ }^{4}$ Similarly, Patel et al ${ }^{34}$ revealed an average flexion in the PCL-deficient knee of $138^{\circ}$ and an average extension loss of only $1^{\circ}$ (range: $0^{\circ}-4^{\circ}$ ). Parolie and Bergfeld ${ }^{6}$ had only one of 25 patients with a loss of $5^{\circ}$ of knee extension compared to the uninvolved knee.

Results in the long-term studies of operative management were variable. Song et $\mathrm{al}^{44}$ showed that 11 of 66 cases had some extension loss $<5^{\circ}$. Jackson et $\mathrm{al}^{26}$ found that compared to the contralateral knee, only 1 of 22 patients had $>3^{\circ}$ of loss of extension and 2 of 22 patients had $>5^{\circ}$ of flexion loss. Shon et al, ${ }^{30}$ in a study of 14 patients, found only one patient to have $10^{\circ}$ flexion limitation compared to the contralateral knee. Hermans et $\mathrm{al}^{25}$ and Lipscomb et $\mathrm{al}^{28}$ reported average mean range of motion (ROM) loss compared to the uninvolved knee, with Hermans et $\mathrm{al}^{25}$ finding a mean loss of $8^{\circ}$ of flexion and Lipscomb et $\mathrm{al}^{28}$ finding an average overall decrease of $9^{\circ}$ of ROM in both the acute and chronic groups.

\section{Strength}

Correlation between the functional outcomes of PCL treatment and return of strength has been variable. Parolie and Bergfeld $^{6}$ and Cross and Powell ${ }^{53}$ reported better subjective results after PCL injury in patients with greater quadriceps muscle strength. Keller et al, ${ }^{16}$ however, found no relationship between quadriceps muscle strength and final outcome after PCL injury. Regardless, patients with PCL tears have been shown to be able to maintain nearly normal strength with nonoperative treatment, with measurements showing mean strength of $>90 \%$ for both hamstring and quadriceps muscles (range: $93 \%-100 \%) .^{3,4,6,34}$ Very few of the long-term studies evaluating PCL reconstruction reported on strength outcomes. Jackson et $\mathrm{al}^{26}$ found that 18 of the 22 patients were able to achieve $>90 \%$ of their contralateral knee distance on single-legged hop test. Lipscomb et $\mathrm{al}^{28}$ found that Cybex evaluations revealed average quadriceps strength deficit of $7 \%-15 \%$ for the acute group and $6 \%-8 \%$ for the group with chronic PCL tears.

\section{Return to activity}

Some studies have recommended surgical management for high-demand athletes or to help patients improve function and increase activity. ${ }^{7}$ The long-term mean Tegner scores for nonoperative studies ranged from 6.6 to 7.7 and the scores for operative studies ranged from 5.7 to 7.4. The NHS found 
a mean Tegner score of $6.9 \pm 1.5$ at a mean of 17.6 years after injury. ${ }^{4}$ At final follow-up, 20 patients (45\%) were still participating in jumping/pivoting sports (levels 8 and 9) at least at the recreational level. Seventeen patients $(38.6 \%)$ had an activity level of 6 or 7 , reporting involvement in recreational sports, such as tennis and golf. Seven patients (16\%) were at level $\leq 5$, indicating that patients were limited to activities of daily living. Other long-term studies of nonoperative treatment for PCL tears have found similarly good results. Dejour et al, ${ }^{15}$ at a mean follow-up of 15 years, concluded that rupture of the PCL did not significantly disturb the resumption of sports. They found that nearly all high-level athletes were able to resume sports at full capacity. Only one athlete, a gymnast, had to abandon competition. Interestingly, they found that patients participating in leisure activities seemed to be more inclined to change or abandon their sports. Boynton and Tietjens ${ }^{14}$ found that at 13.4 years, $26 \%$ of patients had no functional limitations and another $37 \%$ continued to participate in vigorous activities and sports but at a lower performance level. Patel et $\mathrm{al}^{34}$ found that $65 \%$ of patients continued recreational sports, with 24 of them playing at preinjury level and 13 at a decreased level. Dandy and Pusey ${ }^{1}$ reported that only $15 \%$ of patients were no longer able to pursue sporting or recreational activities due to their injury.

Return to activities in studies of operative management of PCL tears showed varied results. Song et $\mathrm{al}^{44}$ found that $58.3 \%$ of patients in the transtibial group and $63.3 \%$ in the tibial inlay group returned to preinjury sports activities. Jackson et al $^{26}$ showed that regular participation in moderate to strenuous activities improved from $26.9 \%$ of patients preoperatively to $88.5 \%$ of patients at final evaluation. Lipscomb et $\mathrm{al}^{28}$ reported that 7 of 14 patients treated acutely were able to return to their previous sports, 4 returned to less strenuous sports, and 3 were unable to return to any sports activities. Seven of 11 patients treated for chronic tears were able to return to their previous sports and 4 returned to less strenuous sports. In an operative study by Chan et al, ${ }^{17}$ they found that many patients lowered their activity levels following reconstruction, "likely reflecting the realization that complete restoration of knee function after reconstructive surgery is extremely rare."

\section{Subjective outcomes}

It is reasonable to believe that surgical intervention is being offered to patients when they continue to experience undesirable symptoms after PCL injury. Many patients with chronic PCL tears continue to have pain and feelings of instability. Dejour et $\mathrm{al}^{15}$ found that of the 45 patients treated nonoperatively, 22 patients had moderate pain related to weather or prolonged effort, 13 had considerable pain that was intermittent, and 6 complained of constant pain. Thirteen of the 45 patients complained of instability, with 4 having only occasional instability, 7 having occasional instability even on flat ground, and 2 complaining of considerable instability on flat ground. Dandy and Pusey ${ }^{1}$ also found complaints of continued pain and instability in several patients, with pain being particularly evident when the knee was in a semi-flexed position. Patel et al, ${ }^{34}$ in a prospective study of PCL injuries, found that $66 \%$ of patients had no pain, $24 \%$ had mild pain, and $10 \%$ had moderate pain on exertion. Of the 57 patients (58 knees), 91\% had no giving way and $9 \%$ complained of occasional giving way, especially when going downstairs. Parolie and Bergfeld ${ }^{6}$ found that $48 \%$ of patients had no pain, $24 \%$ complained of occasional pain, $20 \%$ had pain only with exercise, and $8 \%$ complained of intermittent pain prior to and after exercise. Of the 25 patients, only 3 patients $(12 \%)$ complained of the knee giving way with exercise and $2(8 \%)$ complained of their knee giving way with activities of daily living.

Although PCL reconstruction reduces the amount of posterior laxity, without complete stabilization it is likely that patients will continue to have some pain and feelings of instability. MacGillivray et $\mathrm{al}^{29}$ found that $54 \%$ of patients reported no instability episodes following reconstruction, while $38 \%$ reported rare episodes and $8 \%$ reported occasional episodes. Lipscomb et $\mathrm{al}^{28}$ found that in the acute group, 5 of 14 patients related occasional discomfort and 3 had occasional giving way of their knee. In the chronic group, 4 of 11 patients reported occasional discomfort and 4 continued to have occasional giving way.

Comparison of subjective outcomes is difficult due to the variety of evaluations that have been used to report these outcomes in studies. The most common evaluation used in the long-term studies on operative management was the Lysholm score, while the most common evaluation for the long-term studies on nonoperative management was the International Knee Documentation Committee (IKDC) subjective score. Table 4 reports the results of the Lysholm and IKDC scores at final follow-up. The only nonoperative study to report a Lysholm knee score was Patel et al, ${ }^{34}$ who found an average score of 85.2 , while operative long-term studies reported outcomes ranging from 81 to 92.1 . The NHS reported Cincinnati Knee Rating Scores (CKRS) ${ }^{54}$ and IKDC scores. ${ }^{4}$ The NHS showed a mean CKRS at a mean of 17 years was 81.3; however, no operative studies reported this type of evaluation that makes comparisons difficult. A few of the long-term 
Table 4 Summary of mean subjective scores for nonoperative and operative studies

\begin{tabular}{|c|c|c|}
\hline & Lysholm score & IKDC score \\
\hline \multicolumn{3}{|c|}{ Nonoperative studies } \\
\hline Shelbourne et $\mathrm{al}^{4}$ & & 73.4 \\
\hline Shelbourne et $\mathrm{al}^{5}$ & & 82.7 \\
\hline Patel et $\mathrm{al}^{34}$ & 85.2 & 84 \\
\hline \multicolumn{3}{|l|}{ Operative studies } \\
\hline Hermans et $\mathrm{al}^{25}$ & 75 & 65 \\
\hline MacGillivray et $\mathrm{al}^{29}$ & 81 & \\
\hline Shon et a $\left.\right|^{30}$ & 88.1 & \\
\hline Jackson et $\mathrm{a}^{26}$ & 90 & 87 \\
\hline Song et $\mathrm{al}^{44}$ & $\begin{array}{l}89.9 \text { transtibial, } \\
92.1 \text { tibial inlay }\end{array}$ & \\
\hline
\end{tabular}

Abbreviation: IKDC, International Knee Documentation Committee.

studies did report IKDC scores at final evaluation. The NHS found a mean IKDC score of 73.4. ${ }^{4}$ Patel et al ${ }^{34}$ found a mean IKDC score of 84 at 6.9-year follow-up, and Shelbourne et $\mathrm{al}^{5}$ found a score of 82.7 at 7.8-year follow-up. Although this shows some limitation and subjective complaints by a number of patients, it compares with the long-term IKDC scores in surgical studies of 65 and 87 points by Hermans et $\mathrm{al}^{25}$ and Jackson et al, ${ }^{26}$ at 9 - and 10-year follow-up, respectively. Within the NHS, 40 patients completed $\geq 4$ CKRS evaluations at regular intervals through time. Twenty-five percent of patients were rated as consistently excellent, $5 \%$ were rated as consistently good, $2.5 \%$ were rated as consistently fair, and $2.5 \%$ were rated as consistently poor. Among the patients with inconstant evaluations, $12.5 \%$ had declining scores, $22.5 \%$ had consistently improving scores, and $30 \%$ reported inconsistent scores throughout evaluations. ${ }^{4}$ Although many patients with chronic PCL tears continue to complain of pain and feelings of instability, the NHS found that IKDC scores at an average of 14 years compare favorably with those reported by Hermans et $\mathrm{al}^{25}$ and Jackson et $\mathrm{al}^{26}$ for long-term outcomes of PCL reconstruction. The NHS also found that $23 \%$ of patients continue to improve subjectively with time and many patients, $30 \%$, had inconsistent scores during evaluations. ${ }^{4}$

\section{Osteoarthritis}

Along with restoring stability and improving outcomes, surgical reconstruction of the PCL is often recommended to prevent the future development of osteoarthritis. ${ }^{25}$ In the nonoperative study by Boynton and Tietjens, ${ }^{14}$ osteoarthritis was found in $88 \%$ of patients after meniscal surgery and $60 \%$ of patients that did not undergo meniscal surgery. Several studies have also suggested that the development of osteoarthritis increased with time from injury. ${ }^{15,16}$ Much of the increased research into PCL management has been due to the belief that the natural history of PCL injuries may not be as benign as previously thought. However, as mentioned previously, most of the nonoperative studies were retrospective and of patients seeking treatment for their PCL injury. More recent prospective studies on the natural history of PCL injuries has demonstrated far less degenerative changes. ${ }^{3,4,34}$ Furthermore, reconstruction of the PCL has yet to produce a technique that reliably restores knee stability, which is likely necessary in order to prevent arthritic changes. Among the long-term studies under review in this paper, 4 operative and 5 nonoperative studies reported on the frequency of osteoarthritis. In the NHS, $41 \%$ of patients had some evidence of osteoarthritis at a mean of 14.3 years, but only $11 \%$ of the patients had moderate to severe osteoarthritis. ${ }^{4}$ The overall grade of radiographs were rated as normal in 59\%, nearly normal in 30\%, abnormal in $9 \%$, and severely abnormal in $2 \%$. Only 5 patients (11\%) had medial joint space narrowing $>2.0 \mathrm{~mm}$. Most of the osteoarthritic changes reported in studies on PCL injuries occur in the medial and patellofemoral compartments. The long-term studies on nonoperative management reported osteoarthritis in $17 \%$ to $88 \%$ of patients. Boynton and Tietjens, ${ }^{14}$ as mentioned above, reported the highest amount of osteoarthritis in long-term follow-ups. Parolie and Bergfeld ${ }^{6}$ found evidence of arthritis in 36\% of patients, with 8 graded as mild, 1 as moderate, and none as severe. Dejour et $\mathrm{al}^{15}$ found osteoarthritis, mainly tibiofemoral, in $27 \%$ of patients. Patel et $\mathrm{al}^{34}$ found degenerative changes in $17 \%$ of patients, with mild medial compartment osteoarthritis in 7 knees, moderate medial compartment osteoarthritis in 3 knees, and mild patellofemoral compartment osteoarthritis in 4 knees. The long-term studies on operative management of PCL injuries reported osteoarthritis in $13.3 \%$ to $63.6 \%$ of patients. Lipscomb et $\mathrm{al}^{28}$ found degenerative changes in $42.9 \%$ of patients treated for acute PCL tears and $63.3 \%$ of patients treated for chronic PCL tears. Hermans et $\mathrm{al}^{25}$ reported medial joint line narrowing in 59\% of patients, with IKDC ratings of normal in 9 patients, nearly normal in 10 patients, and abnormal in 3 patients. Jackson et $\mathrm{a}^{26}$ found evidence of osteoarthritis in $36 \%$ of patients, with 4 having osteophytes with normal joint space and 4 having moderate joint space narrowing. Song et $\mathrm{al}^{44}$ found that compared with the uninvolved knee, $16.7 \%$ of patients in the transtibial group and $13.3 \%$ in the tibial inlay group had above grade I osteoarthritic changes. It is believed that due to the biomechanical changes in PCL-deficient knees patients will suffer increased patellofemoral arthritis, leading to pain and difficulty with stairs. It appears, however, 
that this perception may be unsubstantiated by true NHSs. Only 3 patients (7\%) in the NHS had an abnormal grade of patellofemoral arthritis, ${ }^{4}$ which was similar to the rate of $16 \%$ found in the study by Patel et $\mathrm{al}^{34}$ and $11 \%$ found in the study by Boynton and Tietjens. ${ }^{14}$

\section{Complications}

When considering surgical intervention for any medical condition, it is important to weigh the benefits of the operation with the potential risks. In addition to the standard risks associated with any surgical procedure, PCL reconstruction poses some relatively unique potential complications. Along with the more common complications of residual posterior laxity, motion loss, knee pain, and hardware pain, potential rarer complications include neurovascular injury, osteonecrosis, fractures, heterotopic ossification, and compartment syndrome. ${ }^{55}$ Residual posterior laxity is the most common postoperative complication following PCL reconstruction. As mentioned throughout this review, reconstruction of the PCL nearly always reduces posterior laxity but rarely normalizes it. Another complication following PCL reconstruction is loss of range of motion. Unlike reconstruction of the ACL, loss of motion following PCL reconstruction is more likely to be flexion than extension. ${ }^{55}$ Neurovascular injury, although rare, is the most feared complication of PCL reconstruction. Despite the proximity of the neurovascular structures to the PCL, only one case study was found describing a popliteal artery injury during a PCL reconstruction. ${ }^{56}$ Among the long-term studies evaluating operative management of PCL reconstructions, only three reported on complications of the procedures. ${ }^{25,30,44}$ Shon et $\mathrm{al}^{30}$ reported that among both treatment groups, 6 patients had mild anterior knee pain and 2 patients had pain around the staple that resolved after removal of the staple. There were no neurovascular, metal failure, or infections observed. Song et $\mathrm{al}^{44}$ reported that 5 cases in the transtibial group were complicated by saphenous nerve distribution numbness with mild tenderness at the incision site of tendon harvesting and 3 cases in the tibial inlay group had numbness and tenderness with scar discomfort along the posterior incision. There were no vascular complications. Hermans et $\mathrm{al}^{25}$ reported that 4 patients required hardware removal for residual pain and 1 patient required an open capsular release for postoperative arthrofibrosis. There were no infections or neurovascular complications.

\section{Discussion}

The optimal management for PCL injuries continues to be debated among orthopedic surgeons. Due to the risks of surgery, it should be clear that if surgical management is to be recommended to patients, it should improve upon the natural history of the injury. In order to determine this, however, one must first know what the long-term outcomes are of patients treated with nonoperative management. At a mean of 14 years after injury, the NHS found that patients have good subjective and objective outcomes that were not statistically significantly different between grades of PCL laxity. ${ }^{4}$ Due to these good results, we questioned whether surgical management of PCL injuries can improve any of these outcomes at long-term evaluation. In this review, we analyzed 12 other long-term studies and compared the results to the NHS. ${ }^{4}$ We looked at laxity, range of motion, strength, return to activity, symptoms, and prevention of osteoarthritis. We found that outside of laxity, nonoperative management of isolated PCL tears compared favorably with the long-term results of operative management.

Surgical management of PCL injuries is often recommended to patients to regain stability in order to improve subjective outcomes, increase return to sports and activities, and prevent the development of osteoarthritis. Most patients following PCL reconstruction, however, continue to have residual knee laxity found on clinical posterior drawer tests, KT-1000 arthrometer, and Telos stress tests. Although the results are significantly improved, they fail to restore normal stability compared to the nonoperative knee. Without complete restoration of knee stability, we question whether simply reducing laxity will result in any clinical benefit to the patient. The NHS found that the subjective outcomes of patients are unrelated to the degree of laxity, and that subjective outcomes were similar to those reported in longterm follow-up of operative management. ${ }^{4}$ Comparisons are difficult due to differences in evaluation; however, we found a mean IKDC score of 73.4, which compares favorably with 65 and 87 reported by Hermans et $\mathrm{al}^{25}$ and Jackson et $\mathrm{al}^{26}$ at 9- and 10-year follow-ups, respectively. In addition, $23 \%$ of patients continue to improve with time and $30 \%$ of patients had inconsistent scores throughout the 14-year evaluation. Given the comparable subjective outcomes and possibility for further improvement over time, we encourage surgeons to be cautious in immediately offering PCL reconstruction for patients with acute flare-up of symptoms.

It is reasonable to assume that some surgeons recommend surgical management to improve function and return to sports. In a long-term study by Boutefnouchet et al, ${ }^{22}$ they concluded that "with a debatable retardation in the onset of secondary OA and favorable results obtained with functional nonoperative management, the most evident advantage of 
PCL reconstruction is objective return of good level of function." The NHS found, however, that many patients have good return to activity following nonoperative management, with a mean Tegner score of 6.9 at final follow-up. ${ }^{4}$ When looking at whether PCL reconstruction can improve a patient's ability to return to a high level of activity, it is important to first determine whether the procedure is able to reliably restore normal knee stability. Most studies of patients after PCL reconstruction show that patients have residual knee laxity. ${ }^{25,26,29,30,44}$ It is likely that until PCL reconstruction is able to completely restore knee stability, it will not significantly improve return to sports and activities over that of appropriate rehabilitation and strengthening.

Likewise, without complete restoration of normal knee stability, it is unlikely that PCL reconstruction will be able to reduce the incidence of osteoarthritis compared to that of nonoperative management. Long-term studies found osteoarthritis in $17 \%-88 \%$ of patients treated nonoperatively $4,6,14,15,34$ and $13.3 \%-63.6 \%$ of patients following reconstruction. ${ }^{25,26,28,44}$ Although $41 \%$ of patients in the NHS had some osteoarthritic changes, only $11 \%$ had moderate or severe osteoarthritis with only 5 patients $(11 \%)$ having joint line narrowing $>2.0 \mathrm{~mm} .{ }^{4}$ If reconstruction of the PCL is being performed to prevent the future development of osteoarthritis, it appears that, thus far, this goal has not been met.

As with any study on the management of PCL injuries, comparison of results is difficult due to a heterogeneity of patients, differences in treatment and surgical techniques, and differences in outcome evaluations. We attempted to eliminate heterogeneity by only using studies involving patients with isolated PCL tears. Although the NHS study was a minimum 10-year follow-up, we analyzed all studies with a mean follow-up $>6$ years in order to have adequate comparisons in all outcome evaluations. We found that nearly all subjective and objective outcomes in the NHS were similar to those of long-term operative outcomes. The only major difference was an increase in the reduction in laxity with operative management compared to nonoperative management; however, we found no correlation between subjective outcomes and grades of laxity. Furthermore, few patients following reconstruction have completely normal stability.

\section{Conclusion}

The subjective and objective results in the NHS compare favorably to those of long-term outcomes for PCL reconstruction. Unless a technique is found that can completely restore knee stability, it is unlikely that simply reducing posterior laxity will improve outcomes or prevent the development of osteoarthritis.

\section{Disclosure}

None of the authors report any conflicts of interest to disclose related to the content of this review.

\section{References}

1. Dandy DJ, Pusey RJ. The long-term results of unrepaired tears of the posterior cruciate ligament. J Bone Joint Surg Br. 1982;64(1):92-94.

2. Fowler PJ, Messieh SS. Isolated posterior cruciate ligament injuries in athletes. Am J Sports Med. 1987;15(6):553-557.

3. Shelbourne KD, Davis TJ, Patel DV. The natural history of acute, isolated, nonoperatively treated posterior cruciate ligament injuries. A prospective study. Am J Sports Med. 1999;27(3):276-283.

4. Shelbourne KD, Clark M, Gray T. Minimum 10-year follow-up of patients after an acute, isolated posterior cruciate ligament injury treated nonoperatively. Am J Sports Med. 2013;41(7):1526-1533.

5. Shelbourne KD, Muthukaruppan Y. Subjective results of nonoperatively treated, acute, isolated posterior cruciate ligament injuries. Arthroscopy. 2005;21(4):457-461.

6. Parolie JM, Bergfeld JA. Long-term results of nonoperative treatment of isolated posterior cruciate ligament injuries in the athlete. Am J Sports Med. 1986;14(1):35-38.

7. Bedi A, Musahl V, Cowan JB. Management of posterior cruciate ligament injuries: an evidence-based review. J Am Acad Orthop Surg. 2016;24(5):277-289.

8. Cosgarea AJ, Jay PR. Posterior cruciate ligament injuries: evaluation and management. J Am Acad Orthop Surg. 2001;9(5):297-307.

9. Harner CD, Hoher J. Evaluation and treatment of posterior cruciate ligament injuries. Am J Sports Med. 1998;26(3):471-482.

10. Hammoud S, Reinhardt KR, Marx RG. Outcomes of posterior cruciate ligament treatment: a review of the evidence. Sports Med Arthrosc. 2010;18(4):290-291.

11. LaPrade CM, Civitarese DM, Rasmussen MT, LaPrade RF. Emerging updates on the posterior cruciate ligament: a review of the current literature. Am J Sports Med. 2015;43(12):3077-3092.

12. Matava MJ, Ellis E, Gruber B. Surgical treatment of posterior cruciate ligament tears: an evolving technique. J Am Acad Orthop Surg. 2009;17(7):435-446.

13. Montgomery SR, Johnson JS, McAllister DR, Petrigliano FA. Surgical management of PCL injuries: indications, techniques, and outcomes. Curr Rev Musculoskelet Med. 2013;6(2):115-123.

14. Boynton MD, Tietjens BR. Long-term followup of the untreated isolated posterior cruciate ligament-deficient knee. Am J Sports Med. 1996;24(3):306-310.

15. Dejour H, Walch G, Peyrot J, Eberhard P. The natural history of rupture of the posterior cruciate ligament. Rev Chir Orthop Reparatrice Appar Mot. 1988;74(1):35-43. French.

16. Keller PM, Shelbourne KD, McCarroll JR, Rettig AC. Nonoperative treated isolated posterior cruciate ligament injuries. Am J Sports Med. 1993;21(1):132-136.

17. Chan YS, Yang SC, Chang CH, et al. Arthroscopic reconstruction of the posterior cruciate ligament with use of a quadruple hamstring tendon graft with 3- to 5-year follow-up. Arthroscopy. 2006;22(7):762-770.

18. Chen $\mathrm{CH}$, Chen WJ, Shih CH. Arthroscopic reconstruction of the posterior cruciate ligament: a comparison of quadriceps tendon autograft and quadruple hamstring tendon graft. Arthroscopy. 2002;18(6):603-612.

19. Deehan DJ, Salmon LJ, Russell VJ, Pinczewski LA. Endoscopic singlebundle posterior cruciate ligament reconstruction: results at minimum 2-year follow up. Arthroscopy. 2003;19(9):955-962.

20. Fanelli GC, Giannotti BF, Edson CJ. The posterior cruciate ligament arthroscopic evaluation and treatment. Arthroscopy. 1994;10(6):673-688.

21. Kim YM, Lee CA, Matava MJ. Clinical results of arthroscopic singlebundle transtibial posterior cruciate ligament reconstruction: a systematic review. Am J Sports Med. 2011;39(2):425-434.

22. Boutefnouchet T, Bentayeb M, Qadri Q, Ali S. Long-term outcomes following single-bundle transtibial arthroscopic posterior cruciate ligament reconstruction. Int Orthop. 2013;37(2):337-343. 
23. Chen B, Gao S. Double-bundle posterior cruciate ligament reconstruction using a non-hardware suspension fixation technique and 8 strands of autogenous hamstring tendons. Arthroscopy. 2009;25(7):777-782.

24. Garofalo R, Jolles BM, Moretti B, Siegrist O. Double-bundle transtibial posterior cruciate ligament reconstruction with a tendon-patellar bonesemitendinosus tendon autograft: clinical results with a minimum of 2 years' follow-up. Arthroscopy. 2006;22(12):1331-1338.

25. Hermans S, Corten K, Bellemans J. Long-term results of isolated anterolateral bundle reconstructions of the posterior cruciate ligament: a 6- to 12-year follow-up study. Am J Sports Med. 2009;37(8):1499-1507.

26. Jackson WFM, van der Tempel WM, Salmon LJ, Williams HA, Pinczewski LA. Endoscopically-assisted single-bundle posterior cruciate ligament reconstruction: results at minimum ten-year follow-up. J Bone Joint Surg Br. 2008;90(10):1328-1333.

27. Li B, Wen Y, Wu H, Qian Q, Wu Y, Lin X. Arthroscopic single-bundle posterior cruciate ligament reconstruction: retrospective review of hamstring tendon graft versus LARS artificial ligament. Int Orthop. 2009;33(4):991-996.

28. Lipscomb AB, Anderson AF, Norwig ED, Hovis WD, Brown DL. Isolated posterior cruciate ligament reconstruction: long-term results Am J Sports Med. 1993;21(4):490-496.

29. MacGillivray JD, Stein BE, Park M, Allen AA, Wickiewicz TL, Warren RF. Comparison of tibial inlay versus transtibial techniques for isolated posterior cruciate ligament reconstruction: minimum 2-year follow-up Arthroscopy. 2006;22(3):320-328.

30. Shon OJ, Lee DC, Park CH, Kim WH, Jung KA. A comparison of arthroscopically assisted single and double bundle tibial inlay reconstruction for isolated posterior cruciate ligament injury. Clin Orthop Surg. 2010;2(2):76-84.

31. Wajsfisz A, Christel P, Djian P. Does reconstruction of isolated chronic posterior cruciate ligament injuries restore normal knee function? Orthop Traumatol Surg Res. 2010;96(4):388-393.

32. Wu CH, Chen ACY, Yuan LJ, et al. Arthroscopic reconstruction of the posterior cruciate ligament by using a quadriceps tendon autograft: a minimum 5-year follow-up. Arthroscopy. 2007;23(4):420-427.

33. Zhao J, Huangfu X. Arthroscopic single-bundle posterior cruciate ligament reconstruction: retrospective review of 4- versus 7-strand hamstring tendon graft. Knee. 2007;14(4):301-305.

34. Patel DV, Allen AA, Warren RF, Wickiewicz TL, Simonian PT. The nonoperative treatment of acute, isolated (partial or complete) posterior cruciate ligament-deficient knees: an intermediate-term followup study. HSS J. 2007;3(2):137-146.

35. Torg JS, Barton TM, Pavlov H, Stine R. Natural history of posterior cruciate ligament-deficient knee. Clin Orthop Relat Res. 1989;246: 208-216.

36. Ahn JH, Yang HS, Jeong WK, Koh KH. Arthroscopic transtibial posterior cruciate ligament reconstruction with preservation of posterior cruciate ligament fibers: clinical results of minimum 2-year follow-up. Am J Sports Med. 2006;34(2):194-204.

37. Ahn JH, Yoo JC, Wang JH. Posterior cruciate ligament reconstruction: double-loop hamstring tendon autograft versus Achilles tendon allograftclinical results of a minimum 2-year follow-up. Arthroscopy. 2005; 21(8):965-969.

38. Chen CH, Chuang TY, Wang KC, Chen WJ, Shih CH. Arthroscopic posterior cruciate ligament reconstruction with hamstring tendon autograft: results with a minimum 4-year follow-up. Knee Surg Sports Traumatol Arthrosc. 2006;14(11):1045-1054.
39. Houe T. Jorgensen U. Arthroscopic posterior cruciate ligament reconstruction: one- vs. two-tunnel technique. Scand JMed Sci Sports. 2004; 14(2):107-111.

40. Jung YB, Jung HJ, Tae SK, Lee YS, Yang DL. Tensioning of remnant posterior cruciate ligament and reconstruction of anterolateral bundle in chronic posterior cruciate ligament injury. Arthroscopy. 2006; 22(3):329-338.

41. Seon JK, Song EK. Reconstruction of isolated posterior cruciate ligament injuries: a clinical comparison of the transtibial and tibial inlay techniques. Arthroscopy. 2006;22(1):27-32.

42. Wang CJ, Chen HS, Huang TW. Outcome of arthroscopic single bundle reconstruction for complete posterior cruciate ligament tear. Injury. 2003;34(10):747-751.

43. Wang CJ, Weng LH, Hsu CC, Chan YS. Arthroscopic single- versus double-bundle posterior cruciate ligament reconstructions using hamstring autograft. Injury. 2004;35(12):1293-1299.

44. Song EK, Park HW, Ahn YS, Seon JK. Transtibial versus tibial inlay techniques for posterior cruciate ligament reconstruction: long-term follow-up study. Am J Sports Med. 2014;42(12):2964-2971.

45. Ahn JH, Lee SH, Choi SH, Wang JH, Jang SW. Evaluation of clinical and magnetic resonance imaging results after treatment with casting and bracing for the acutely injured posterior cruciate ligament. Arthroscopy. 2011;27(12):1679-1687.

46. Akisue T, Kurosaka M, Yoshiya S, Kuroda R, Mizuno K. Evaluation of healing of the injured posterior cruciate ligament: analysis of instability and magnetic resonance imaging. Arthroscopy. 2001;17(3):264-269.

47. Jacobi M, Reischl N, Wahl P, Gautier E, Jakob RP. Acute isolated injury of the posterior cruciate ligament treated by a dynamic anterior drawer brace: a preliminary report. J Bone Joint Surg Br. 2010;92(10): 1381-1384.

48. Jung YB, Jung HJ, Yang JJ, Yang DL, Lee YS, Song IS, Lee HJ. Characterization of spontaneous healing of chronic posterior cruciate ligament injury: analysis of instability and magnetic resonance imaging. J Magn Reson Imaging. 2008;27(6):1336-1340.

49. Shelbourne KD, Jennings RW, Vahey TN. Magnetic resonance imaging of posterior cruciate ligament injuries: assessment of healing. $\mathrm{Am} \mathrm{J}$ Knee Surg. 1999;12(4):209-213.

50. Tewes DP, Fritts HM, Fields RD, Quick DC, Buss DD. Chronically injured posterior cruciate ligament: magnetic resonance imaging. Clin Orthop Relat Res. 1997;335:224-232.

51. Jenner JM, van der Hart CP, Willems WJ. Mid-term results of arthroscopic reconstruction in chronic posterior cruciate ligament instability. Knee Surg Sports Traumatol Arthrosc. 2006;14(9):848-853.

52. Zhao J, Xiaoqiao H, He Y, Yang X, Liu C, Lu Z. Sandwich-style posterior cruciate ligament reconstruction. Arthroscopy. 2008;24(6):650-659.

53. Croparolies MJ, Powell JF. Long-term followup of posterior cruciate ligament rupture: a study of 116 cases. Am J Sports Med. 1984;12(4): 292-297.

54. Barber-Westin SD, Noyes FR, McCloskey JW. Rigorous statistical reliability, validity, and responsiveness testing of the Cincinnati knee rating system in 350 subjects with uninjured, injured, or anterior cruciate ligament-reconstructed knees. Am J Sports Med. 1999;27:402-416.

55. Zawodny SR, Miller MD. Complications of posterior cruciate ligament surgery. Sports Med Arthrosc. 2010;18(4):269-274.

56. Cenni MH, do Nascimento BF, Carneiro GG, de Andrade RC, Pinheiro Jr LF, Nicolai OP. Popliteal artery injury during posterior cruciate ligament reconstruction. Rev Bras Ortop. 2015;50(3):348-351. 


\section{Publish your work in this journal}

Orthopedic Research and Reviews is an international, peer-reviewed, open access journal that focusing on the patho-physiology of the musculoskeletal system, trauma, surgery and other corrective interventions to restore mobility and function. Advances in new technologies, materials, techniques and pharmacological agents are particularly

welcome. The manuscript management system is completely online and includes a very quick and fair peer-review system, which is all easy to use. Visit http://www.dovepress.com/testimonials.php to read real quotes from published authors.

Submit your manuscript here: https://www.dovepress.com/orthopedic-research-and-reviews-journal 